\title{
Vivax Malaria Infection Manifesting as Fulminant Hepatic Failure: A Case Report
}

\author{
Vishnu Kumar Goyal ${ }^{\mathrm{a}}$, Narendra P. Chhangani ${ }^{\mathrm{a}}$, Rakesh Jora ${ }^{\mathrm{a}}$, Sridevi Sundararajan ${ }^{\mathrm{a}, \mathrm{b}}$
}

\begin{abstract}
Here we report a 3-year-old male child who presented with features of fulminant hepatic failure (FHF) and underlying turned out to be P. vivax malaria. Patient showed dramatic response to injection quinine. Though hepatic dysfunction is a known manifestation of $\mathrm{P}$. vivax malaria, FHF is rare.
\end{abstract}

Keywords: Vivax malaria; Fulminant hepatic failure; Artesunate resistance

\section{Introduction}

Malaria continues to be a global health problem with over $40 \%$ of world's population at risk for malaria. Timely diagnosis and administration of antimalarial drugs may be life saving particularly in severe malaria. Though Plasmodium falciparum is the most common, P. vivax and P. knowlesi infection may also result in severe malaria [1]. Hepatitis is a known manifestation of severe malaria, but fulminant hepatic failure (FHF) is rare. In malaria, FHF has been described mainly in association with P. falciparum or mixed infections [2-4]. FHF in P. vivax monoinfection is very rare in children $[5,6]$.

\section{Case Report}

A 3-year-old male child weighing $10 \mathrm{~kg}$ was admitted to our Pediatric Intensive Care Unit with complaints of high grade fever for 5 days, vomiting for 3 days, yellowish discoloration of urine for 2 days, depressed sensorium for 1 day and multi-

\footnotetext{
Manuscript accepted for publication February 17, 2015

aDr. S.N. Medical College, Umaid Hospital for Women and Children, Jodhpur, Rajasthan 342001, India

${ }^{b}$ Corresponding Author: Sridevi Sundararajan, Dr. S.N. Medical College, Umaid Hospital for Women and Children, Jodhpur, Rajasthan 342001, India. Email: devisujee@gmail.com
}

doi: http://dx.doi.org/10.14740/ijcp182w ple episodes of generalized convulsions for $6 \mathrm{~h}$. Three days of oral medications at home were ineffective. Past history was not contributory and development was appropriate for age.

On admission child was stuporous responding only to deep painful stimulus. He was febrile (axillary temperature $102^{\circ} \mathrm{F}$ ), with heart rate 120 per minute, respiratory rate 40 per minute and blood pressure 90/60 $\mathrm{mm} \mathrm{Hg}$. He had pallor and icterus. Fetor hepaticus was present. In neurological examination bilateral pupils were constricted and reactive to light. Signs of increased intracranial pressure, meningeal irritation and focal neurological signs were absent. Tone was decreased, deep tendon reflexes were brisk and bilateral plantar reflexes were up going. Abdomen was distended. Liver was palpable 3 $\mathrm{cm}$ below right costal margin with firm consistency. Liver span was $8 \mathrm{~cm}$. Spleen was palpable $1 \mathrm{~cm}$ from left costal margin with soft consistency. Shifting dullness was present. Rest of the systemic examination was not remarkable. He was managed on the line of hepatic encephalopathy.

Investigations revealed anemia, thrombocytopenia (hemoglobin $8.5 \mathrm{~g} / \mathrm{dL}$, hematocrit $27.3 \%$, total leucocyte count 7,330 cells $/ \mathrm{mm}^{3}$, platelets 66,000 cells $/ \mathrm{mm}^{3}$, peripheral blood, normocytic-normochromic RBC, thrombocytopenia and reticulocyte count 7\%) and deranged liver function tests (serum bilirubin total $8.39 \mathrm{mg} / \mathrm{dL}$ with direct $3.80 \mathrm{mg} / \mathrm{dL}$, SGOT 2,880 IU/L, SGPT, 3,640 IU/L, alkaline phosphatase $618 \mathrm{IU} / \mathrm{L}$, serum albumin $2.7 \mathrm{~g} / \mathrm{dL}$, prothrombin time 40 with PT INR 3). Renal function tests (serum urea $26 \mathrm{mg} / \mathrm{dL}$, serum creatinine $0.82 \mathrm{mg} / \mathrm{dL}$, serum uric acid $3.6 \mathrm{mg} / \mathrm{dL}$ and serum electrolytes (sodium $138 \mathrm{mEq} / \mathrm{L}$, potassium $4.2 \mathrm{mEq} / \mathrm{L}$, total calcium 9.3 $\mathrm{mg} / \mathrm{dL}$ ) were normal. Rapid malaria antigen test was positive for P. vivax and negative for P. falciparum. Widal test (To titer $1 / 40, \mathrm{TH} 1 / 80$ ) and viral markers for hepatitis $\mathrm{A}, \mathrm{B}, \mathrm{C}$, and $\mathrm{E}$ (HBs antigen, IgM anti-HAV, IgM anti-HEV and IgM anti-HCV) all were negative. Tests for dengue (IgM, IgG antibody and NS1 antigen) were also negative. Ultrasonography showed mild pleural effusion on right side, moderate ascites, hepatomeagly (length $12 \mathrm{~cm}$ ) with altered echotexture and splenomegaly (length $13 \mathrm{~cm}$ ).

After malaria antigen report injection artesunate was added but showed no response even after $48 \mathrm{~h}$ of parenteral therapy; high grade fever persisted, abdominal distension increased, liver size increased and urine output decreased. Prothrombin time and partial thromboplastin time remained deranged despite 3 days of injection vitamin $\mathrm{K}$. He had upper gastrointestinal bleed necessitating fresh frozen plasma transfusion twice. 
Blood culture and urine culture were negative.

Keeping a possibility of artesunate resistant vivax malaria leading to FHF, injection artesunate was replaced by injection quinine. After $48 \mathrm{~h}$ of injection quinine, child showed dramatic improvement. Fever spikes decreased, level of consciousness improved, abdominal distension decreased, urine output increased, bleeding stopped and child started taking orally. At 6 weeks follow-up all repeat investigations (platelet count, liver function tests including PT and aPTT and USG chest and abdomen) were normal.

\section{Discussion}

P. vivax malaria once considered to be a benign disease, now has been increasingly causing severe malaria [7]. Recent studies have shown that risk of complications such as anemia, thrombocytopenia, liver dysfunction, renal dysfunction, ARDS, and cerebral malaria is same both in P. vivax and P. falciparum malaria $[8,9]$. Besides affecting multiple organs, P. vivax alone has the potential to cause even multi-organ dysfunction syndrome (MODS) $[10,11]$. Our case also had multiorgan involvement (hepatic dysfunction, deranged coagulation profile, encephalopathy, ascites, pleural effusion, thrombocytopenia and anemia).

Deranged liver function test has been observed in $6.6 \%$ children with P. vivax monoinfection [9]. This percentage may be increased to $26.2 \%$ in P. vivax severe malaria, but FHF is very rare [10]. Differentiation from viral etiology is important, as prognosis is better when underlying cause is malaria. Persistent fever, disproportionate anemia, oliguria and increased liver span favor malarial etiology [11]. Rise in serum levels of hepatic enzyme is low in malaria induced hepatic dysfunction in comparison to viral hepatitis. But in malaria associated FHF hepatic enzymes may be very high $[5,6]$, like in our case.

Previously it was believed that in P. vivax associated severe malaria, hidden coinfection with $\mathrm{P}$. falciparum leads to all complications. But recent studies have proved that $\mathrm{P}$. vivax monoinfection can also result in severe malaria $[12,13]$. WHO recommends artesunate based combination therapy as a first line treatment for all severe malaria cases irrespective of plasmodium species [1]. But artemisinin resistance among P. falciparum is now gradually emerging [14-16] and very rarely $P$. vivax may also be resistant to artesuntate [17], as in our case.

\section{Conclusion}

A possibility of vivax malaria should also strike the treating clinician while dealing a case of FHF.

\section{References}

1. Management of severe malaria: A practical hand book (third edition) 2012. World Health Organization Avenue Appia. 20, 1211 Geneva, Switzerland.

2. Joshi YK, Tandon BN, Acharya SK, Babu S, Tandon M.
Acute hepatic failure due to Plasmodium falciparum liver injury. Liver. 1986;6(6):357-360.

3. Thakur N, Sodani R, Chandra J, Mahto D. A Rare Case Report of Fatal Fulminant Hepatic Failure in a Child due to Mixed vivax and falciparum Infection. Case Rep Pediatr. 2011;2011:614054.

4. Bansal R, Kadhiravan T, Aggarwal P, Handa R, Biswas A, Wali JP. Plasmodium vivax and hepatitis E co-infection-a rare cause of malarial jaundice. Indian J Gastroenterol. 2002;21(5):207-208.

5. Gupta HV, Ruku. Plasmodium vivax malaria presenting with acute liver failure: a rare case report. Int $\mathrm{J}$ of basic and applied Med Scien. 2013;3(2):8-9.

6. Nigam $\mathrm{P}$, Indulkar $\mathrm{M}$, Bansod A. Impending hepatic failure due to Plasmodium vivax Malaria: a case report. International Journal of Medical Research and Review. 2014;2(2):156-158.

7. Limaye CS, Londhey VA, Nabar ST. The study of complications of vivax malaria in comparison with falciparum malaria in Mumbai. J Assoc Physicians India. 2012;60:15-18.

8. Goyal JP, Makwana AM. Comparison of Clinical Profile between $\mathrm{P}$. vivax and $\mathrm{P}$. falciparum Malaria in Children: A Tertiary Care Centre Perspective from India. Malar Res Treat. 2014;2014:132672.

9. Singh R, Kumar S, Rana SK, Thakur B, Singh SP. A comparative study of clinical profiles of vivax and falciparum malaria in children at a tertiary care centre in uttarakhand. J Clin Diagn Res. 2013;7(10):2234-2237.

10. Mehndiratta S, Rajeshwari K, Dubey AP. Multiple-organ dysfunction in a case of Plasmodium vivax malaria. J Vector Borne Dis. 2013;50(1):71-73.

11. Bhalla A, Suri V, Singh V. Malarial hepatopathy. J Postgrad Med. 2006;52(4):315-320.

12. Kochar DK, Tanwar GS, Khatri PC, Kochar SK, Sengar GS, Gupta A, Kochar A, et al. Clinical features of children hospitalized with malaria--a study from Bikaner, northwest India. Am J Trop Med Hyg. 2010;83(5):981989.

13. Kochar DK, Das A, Kochar SK, Saxena V, Sirohi P, Garg S, Kochar A, et al. Severe Plasmodium vivax malaria: a report on serial cases from Bikaner in northwestern India. Am J Trop Med Hyg. 2009;80(2):194-198.

14. Djimde AA, Fofana B, Sagara I, Sidibe B, Toure S, Dembele D, Dama S, et al. Efficacy, safety, and selection of molecular markers of drug resistance by two ACTs in Mali. Am J Trop Med Hyg. 2008;78(3):455-461.

15. Mok S, Imwong M, Mackinnon MJ, Sim J, Ramadoss R, Yi P, Mayxay M, et al. Artemisinin resistance in Plasmodium falciparum is associated with an altered temporal pattern of transcription. BMC Genomics. 2011;12:391.

16. Bhattacharyya N, Mukherjee H, Bose D, Roy S, Das S, Tripathy S, Hati AK. Clinical Case of Artesunate Resistant Plasmodium falciparumMalaria in Kolkata: A First Report. J TropDis. 2:128. doi://dx.doi.org/4172/2329891X.1000128.

17. Melmane P, Shetty S, Gulati D. A study of drug resistance in malaria. JIACM. 2014;15(1):9-12. 